REVIEW ARTICLE

P.W.A. Willems

R.I. Farb

R. Agid

\title{
Endovascular Treatment of Epistaxis
}

\begin{abstract}
SUMMARY: Epistaxis is a common condition that can be managed conservatively in most cases. When these measures, including anterior and posterior packing of the nasal cavity, are unsuccessful at controlling the bleeding, interruption of the blood supply to the sinonasal area can be performed, either by surgical ligation or by transarterial embolization. Embolization should be preceded by thorough diagnostic angiography. Aside from aiding with subsequent selective catheterization and embolization, such angiography may reveal significant anatomic anomalies, anastomoses, or an unsuspected cause of epistaxis. Taking these findings into account, the interventionalist may decide to refrain from embolization or adjust the technique to minimize the risk of adverse events, which are mostly related to inadvertent embolization of the internal carotid artery or ophthalmic artery. We present a review of the various causes of epistaxis and the treatment options, with emphasis on endovascular embolization. We also describe the protocol of our institution for endovascular management of this condition.
\end{abstract}

E pistaxis is a common medical condition, with approximately $60 \%$ of the adult population having experienced at least 1 episode during their lives. Fortunately, most cases resolve spontaneously, and only $6 \%$ of epistaxis cases require medical attention, ${ }^{1}$ accounting for $0.46 \%$ of all emergency department visits in the Unites States. ${ }^{2}$ Large series have shown epistaxis to be equally frequent in males and females. The age distribution exhibits a mild peak before 20 years of age and a more prominent age-related increase after 40 years of age. ${ }^{2,3}$ The latter increase may reflect the increase of vascular disease, hypertension, iatrogenic and pathologic bleeding, and falls as a cause of trauma. Seasonal variation has also been well documented, with an incidence increase during winter months. ${ }^{4,5}$ This may reflect the influence of humidity, temperature, and the greater prevalence of upper respiratory infections.

Most cases of epistaxis arise from the anterior septal area, also known as the Little area. This area is vascularized by the Kiesselbach plexus, which is supplied by branches of the external carotid artery (ECA), including the sphenopalatine artery (SPA), descending palatine artery (DPA), and superior labial artery (SLA), as well as the anterior and posterior ethmoidal arteries (AEA and PEA), which branch off the ophthalmic artery (OphA). ${ }^{6}$ Because this area is readily accessible, hemorrhage from this region can usually be managed by applying pressure to the nostrils, chemical or electrocautery, topical hemostatic or vasoconstricting agents, cryotherapy, hot water irrigation, or anterior nasal packing together with the management of underlying risk factors such as hypertension and oral anticoagulation. $^{7}$

In only approximately $5 \%$ of cases, the origin of the epistaxis lies more posteriorly on the nasal cavity, causing these initial measures to fail. ${ }^{8}$ In most cases, an attempt will be made to control such posterior bleeding with the application of anterior and posterior packs (AP packs). These packs should be applied with care and under patient monitoring because they can lead to nasal trauma, vagal response, aspiration, infection, and airway obstruction, leading to hypoxia, myocardial in-

From the Division of Neuroradiology, Department of Medical Imaging, Toronto Western Hospital, Toronto, Ontario, Canada.

Please address correspondence to P.W.A. Willems, MD, Toronto Western HospitalDepartment of Medical Imaging, 399 Bathurst St, Toronto, ON, Canada, M5T 2S8T; e-mail: pwawillems@gmail.com

Indicates open access to non-subscribers at www.ajnr.org

DOI 10.3174/ajnr.A1607 farction, and even death. ${ }^{7,9}$ Their success rate has been reported to lie between $48 \%$ and $83 \% .^{10-12}$ In the remaining patients, bleeding either continues despite packing or recurs after removal of the AP packs. Subsequent treatment can consist of either surgical ligation or endovascular embolization of the arteries supplying the posterior nasal fossa. Historically, the definitive treatment for intractable posterior epistaxis consisted of transantral surgical ligation of branches of the internal maxillary artery (IMA), with or without ligation of the AEA. More recently, endoscopic surgical procedures have been described for direct cauterization of the active bleeding site or ligation of the SPA. ${ }^{13-16}$ Endovascular treatment of epistaxis was first presented as an alternative to surgery by Sokoloff et al in $19744^{17}$ and consisted of particle embolization of the ipsilateral IMA. The technique was later refined by Lasjaunias et al, ${ }^{18}$ stressing the need for a standardized angiographic and therapeutic approach. It has gained increased acceptance, and several large series have been reported. ${ }^{19,20}$

\section{Preembolization Angiography and Vascular Anatomy}

Lasjaunias et $\mathrm{al}^{18}$ stressed the importance of obtaining a diagnostic preembolization angiogram of the internal carotid artery (ICA) and ECA. In a minority of cases, this may reveal specific abnormalities indicating the cause and location of the hemorrhage. These include contrast extravasation, a tumor blush, a vascular malformation, a traumatic pseudoaneurysm, or another unusual ICA source of epistaxis. Furthermore, angiography enables identification of vascular anomalies, variants, or anastomoses between the ECA and ICA or OphA that could increase the risk of complications, such as stroke or blindness during embolization. These findings may influence the embolization protocol or even lead to aborting the procedure and referral to surgery.

The normal sinonasal vascular anatomy is presented in Fig 1. The terminal branch of the IMA, the SPA, provides the dominant supply to the nasal cavity. The roof of the nasal cavity is supplied by the AEA and PEA, which branch off the OphA. The floor of the nasal cavity is supplied by the ascending palatine artery (APA) and DPA, branches of the facial artery (FA) and IMA respectively. Finally, minor supply is provided anteriorly by the SLA, a branch of the FA, and posteriorly by branches from the ascending pharyngeal artery (APhA).

Even in the absence of vascular anomalies or clearly visible anastomoses, a number of small vessels still serve as potential connections between the ECA and ICA. These include the ar- 


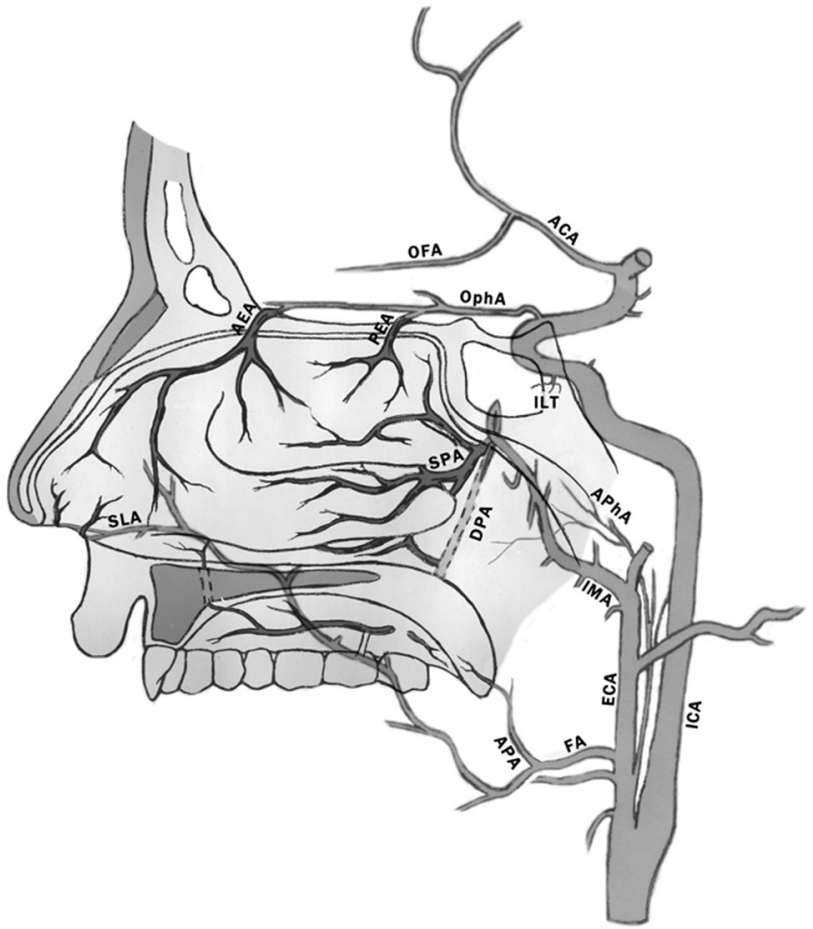

Fig 1. Schematic representation of normal arterial anatomy of the sinonasal region. ACA indicates anterior cerebral artery; AEA, anterior ethmoidal artery; APA, ascending palatine artery; $\mathrm{APhA}$, ascending pharyngeal artery; DPA, descending palatine artery; ECA, external carotid artery; FA, facial artery; ICA, internal carotid artery; ILT, inferior lateral trunk; IMA, internal maxillary artery; OFA, orbitofrontal artery; OphA, ophthalmic artery; PEA, posterior ethmoidal artery; SLA, superior labial artery; SPA, sphenopalatine artery.

tery of the foramen rotundum, the vidian artery, the middle meningeal artery (MMA), the accessory meningeal artery, the APha, the inferolateral trunk (ILT), the meningohypophysial trunk, and communications between the FA, SPA, and OphA. ${ }^{21,22}$ These "dangerous" anastomoses may open in case of increased pressure during embolization. Inadvertent embolization of the ICA or OphA through these anastomoses may lead to stroke or unilateral blindness, respectively. Furthermore, embolization of the OphA can also occur if it is supplied by the ECA instead of the ICA, either due to an anatomic variation or due to collateralization in the face of ICA stenosis.

\section{Embolization in Idiopathic Posterior Epistaxis}

The distribution of causes of epistaxis differs per center, depending on the type of population it serves and the referral patterns. Generally, at least $70 \%$ of cases are idiopathic. ${ }^{19,20}$ In most of these cases, findings of angiography will be normal. This normal initial angiographic finding likely relates to the AP packs, which are invariably in place, tamponading the bleeding site. In these cases, a routine embolization protocol is used, with the goal of diminishing flow to the bleeding mucosa but allowing sufficient collateral flow to avoid necrosis. Because embolization through the ICA, OphA, and APhA cannot be considered safe, the single most important vessel to embolize is the ipsilateral IMA and its branches. Due to the anastomoses between ICA and ECA described above, embolization should only be performed with a stable microcatheter position sufficiently distal to the origins of the accessory meningeal artery and the MMA. Placing the microcatheter distal to the middle deep temporal artery (MDTA) as well may avoid

\begin{tabular}{|c|c|c|}
\hline \multicolumn{3}{|c|}{$\begin{array}{l}\text { Treatment protocol used at our institution for the embolization of } \\
\text { idiopathic posterior epistaxis }\end{array}$} \\
\hline Step & Action & Clarification \\
\hline 1 & Angiogram of il* ICA & $\begin{array}{l}\text { Verify supply to the OphA and } \\
\text { choroidal blush from the } \\
\text { ICA; rule out an ICA source } \\
\text { of bleeding; check for } \\
\text { extensive supply to nasal } \\
\text { mucosa from the EAs }\end{array}$ \\
\hline 2 & Angiogram of il ECA & $\begin{array}{l}\text { Rule out vascular anomalies; } \\
\text { check for dangerous } \\
\text { anastomoses between ECA } \\
\text { and ICA; rule out } \\
\text { nonidiopathic causes of } \\
\text { epistaxis }\end{array}$ \\
\hline 3 & Embolization of il IMA & $\begin{array}{l}\text { Selective catheterization of } \\
\text { IMA, distal to MDTA, and } \\
\text { embolization with } \\
\text { suspension of PVA particles } \\
(250-350 \mu \mathrm{m}) \text { in contrast } \\
\text { medium; sometimes } \\
\text { followed by } 1 \text { or } 2 \text { Gelfoam } \\
\text { pledgets }\end{array}$ \\
\hline 4 & Embolization of il FA & $\begin{array}{l}\text { Performed if significant supply } \\
\text { to nasal mucosa from FA; } \\
\text { selective catheterization of } \\
\text { FA, distal to SMA, and } \\
\text { embolization with } \\
\text { suspension of PVA particles } \\
(250-350 \mu \mathrm{m}) \text { in contrast } \\
\text { medium }\end{array}$ \\
\hline 5 & Repeat $1-4$ on $\mathrm{cl}^{*}$ side & $\begin{array}{l}\text { Due to collaterals between il } \\
\text { and cl vasculature, we } \\
\text { routinely include the } \mathrm{cl} \text { side } \\
\text { in our protocol }\end{array}$ \\
\hline 6 & Transfer to ENT department & $\begin{array}{l}\text { The packs are usually } \\
\text { removed the following day } \\
\text { by the ENT department }\end{array}$ \\
\hline
\end{tabular}

Note:-il indicates ipsilateral; $\mathrm{Cl}$, contralateral; ENT, ear-nose-throat; EAs: ethmoidal arteries (anterior and posterior); ICA, internal carotid artery; OphA, ophthalmic artery; ECA, external carotid artery; IMA, internal maxillary artery; MDTA, middle deep temporal artery; PVA, polyvinyl alcohol; FA, facial artery; SMA, submandibular artery.

* il and cl indicate the side of bleeding or, if the patient bleeds from both nostrils, the side where bleeding started.

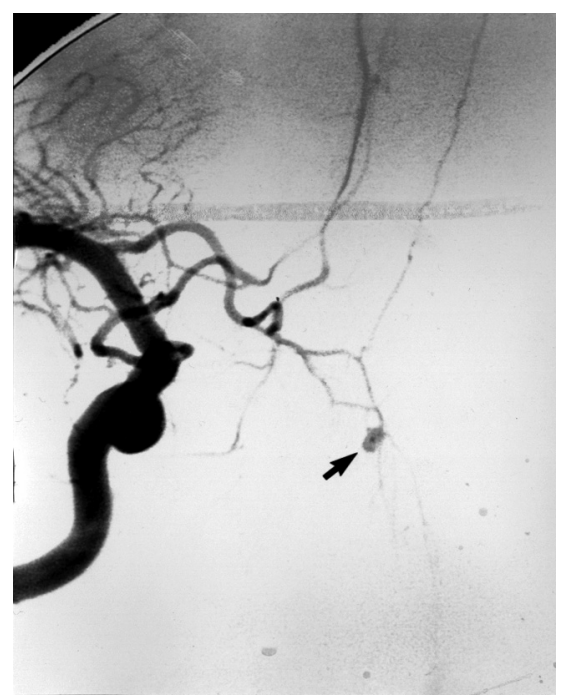

Fig 2. Oblique view of a right internal carotid arteriogram in a 19-year-old man, presenting with uncontrollable epistaxis 2 weeks after being struck in the face by a baseball bat, demonstrating a 5-mm pseudoaneurysm (arrow) arising from an AEA. 

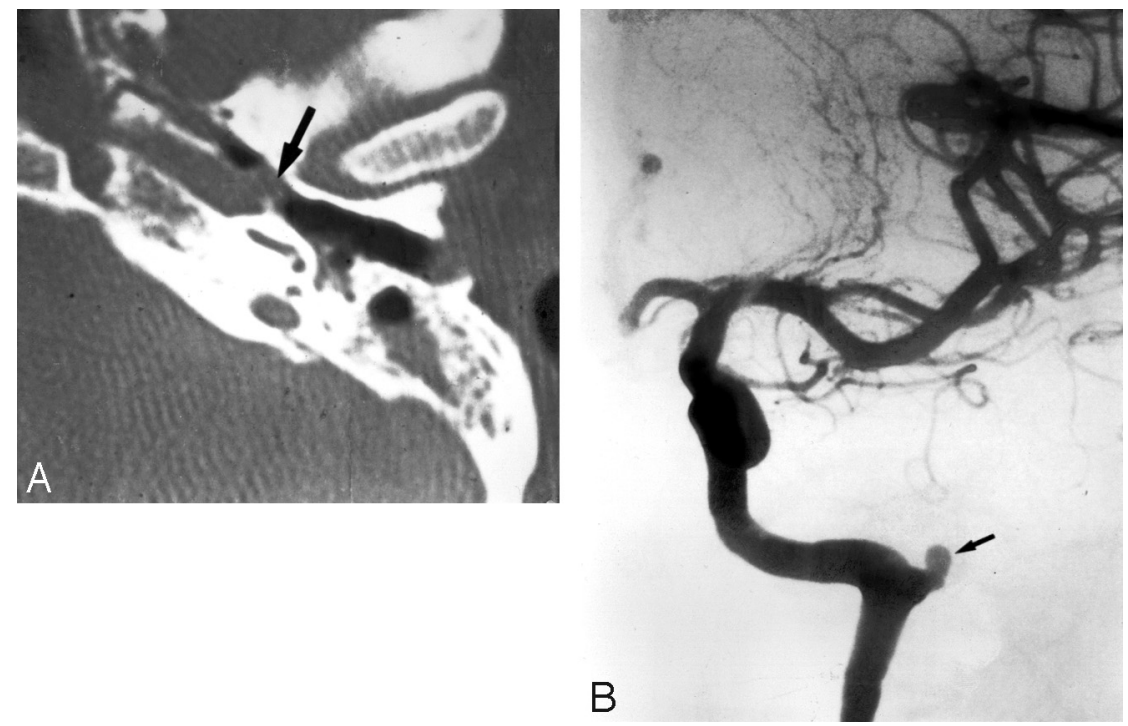

Fig 3. A 35-year-old woman, who presented with severe recurrent epistaxis. $A$, Nonenhanced axial CT scan shows a soft-tissue attenuation projecting from the carotid canal into the eustachian tube (arrow). B, AP view of a left internal carotid arteriogram, revealing a 6-mm aneurysm (arrow) projecting off the region of the petrous genu.

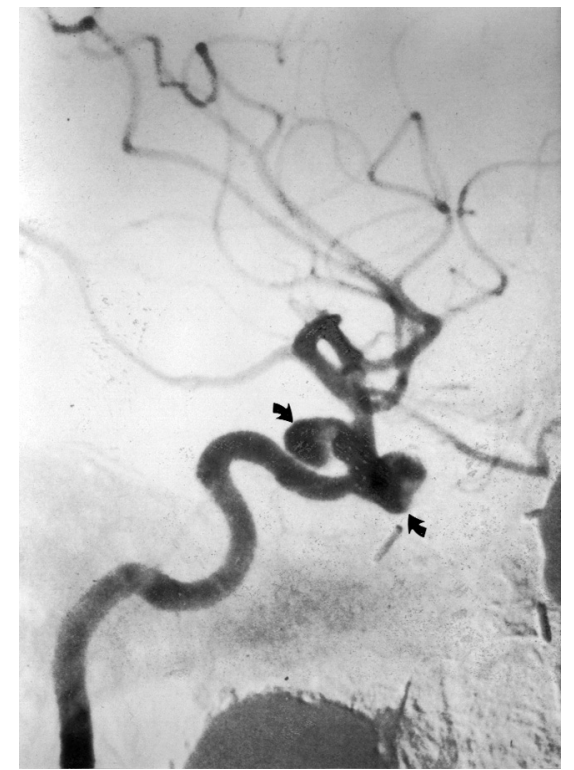

Fig 4. Oblique right internal carotid arteriogram of a 52 -year-old woman with a 6-month history of severe recurrent epistaxis following a motor vehicle crash, revealing 2 large intracavernous traumatic pseudoaneurysms (curved arrows).

postembolization pain and trismus. A suspension of embolic and contrast material is subsequently injected under fluoroscopic control, until significant flow reduction is noted in the IMA branches. Injection of embolic material should not be overly powerful, to avoid reflux of embolic material into dangerous anastomoses. A wedged catheter position should also be avoided because this will allow buildup of injection pressure opening up dangerous anastomoses.

When the embolization is performed in a flow-guided fashion, embolization of the OphA may still occur if it is supplied by the ECA instead of the ICA. Therefore, one should confirm choroidal blush from the ICA, before embolization. Additional embolization of the ipsilateral FA has been reported to increase the success rate. ${ }^{23}$ In this case, the catheter should be placed beyond the submandibular artery to avoid emboliza- tion of the submandibular gland. ${ }^{24}$ Some authors will also embolize the contralateral IMA and even the contralateral FA, especially when these show substantial collateral supply. ${ }^{25}$ The Table outlines the protocol used at our institution for embolization of intractable idiopathic posterior epistaxis.

Performing the embolization with the benefit of general anesthesia is usually preferable for both the patient and interventionalist. To perform this procedure swiftly, safely, and effectively, we require the patient to lie quietly in the supine position. This is best accomplished with intubation and control of the airway should bleeding occur during the procedure, despite the packs. Materials frequently used for embolization include pledgets of gelatin sponge (Gelfoam; Pfizer, New York, NY); Gelfoam powder (Pfizer); polyvinyl alcohol (PVA) particles, ranging in size from 50 to $700 \mu \mathrm{m}$; platinum coils; or a combination of materials. ${ }^{6}$ Swine experiments have shown that different-sized materials cause the same sharp drop in nasal blood flow to a still viable level. Blood flow returned to baseline in 2-8 days, depending on the size of the material used, with smaller particles causing a longer effect. ${ }^{26}$ Midsized embolic material may balance the duration of therapeutic effect against the risk of ischemia, which could result in necrosis or cranial nerve palsy. Smaller particles $(50-150 \mu \mathrm{m})$ are also discouraged because they are more likely to enter dangerous anastomoses. Thus, most recent reports mention the use of PVA particles, ${ }^{27-32}$ usually between 150 and $500 \mu \mathrm{m}$, with or without the subsequent addition of Gelfoam sponge pledgets or platinum coils. ${ }^{29,32}$

The literature is inconsistent with regard to the timing of AP pack removal. Some authors do not remove the packs immediately, presumably expecting the combination of treatments to increase the overall success rate. ${ }^{30,33}$ Others remove the packs in the angiography suite, allowing them to perform additional embolization if bleeding has not yet ceased. ${ }^{19,20,25}$

\section{Other Causes of Intractable Epistaxis}

In a minority of cases, a clear cause for the epistaxis will be known or found during angiography. Because the causes may 

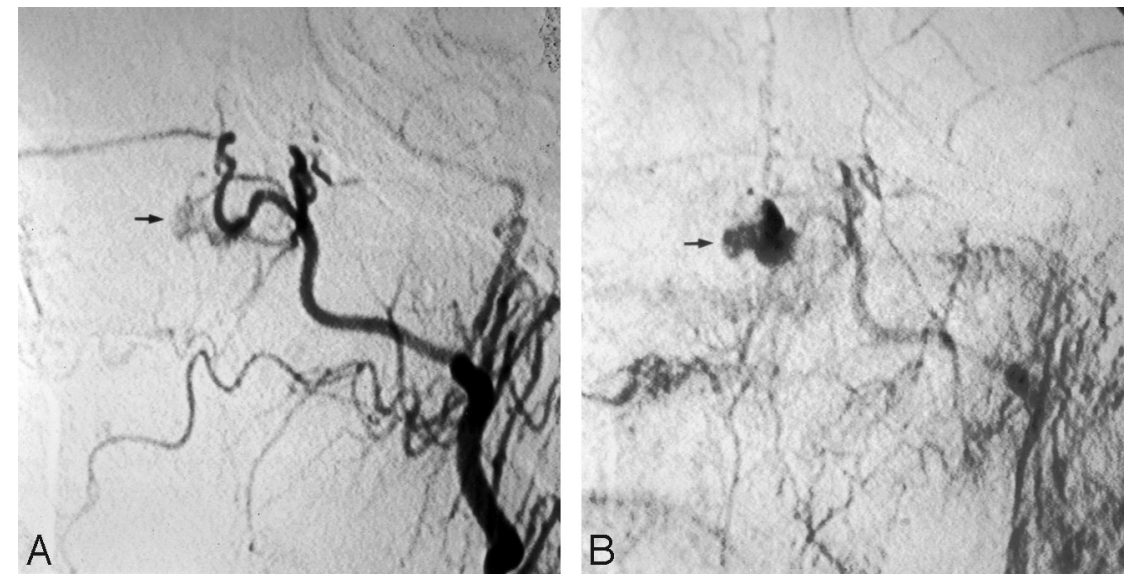

Fig 5. Left external carotid arteriography in a 26-year-old woman presenting with unrelenting epistaxis several hours after septorhinoplasty. Mid $(A)$ and late $(B)$ arterial phases demonstrate contrast extravasation (arrow), indicating the site of hemorrhage.
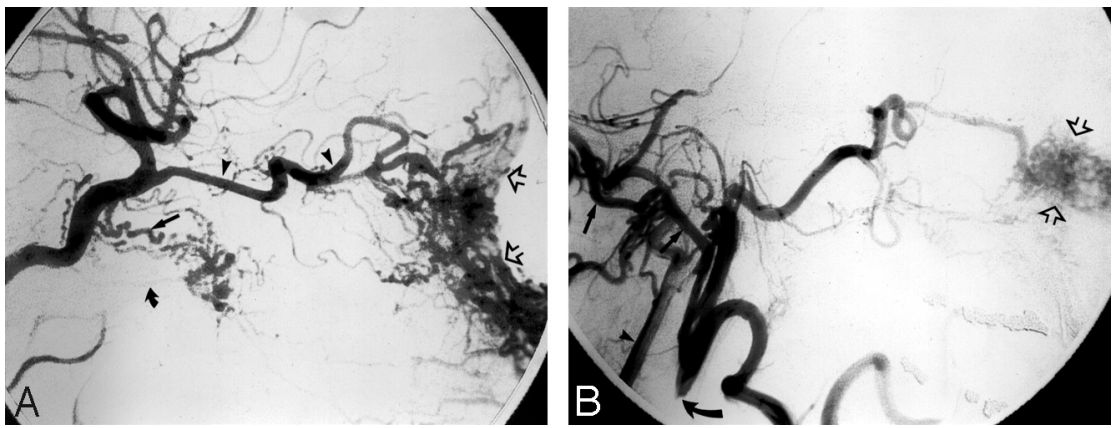

Fig 6. Angiographic imaging of a 35-year-old man with a history of recurrent epistaxis due to an AVM of the nose and upper lip. He had undergone previous surgical ligation of the proximal right ECA. A, Lateral view of a right internal carotid arteriogram demonstrates a large AVM (open arrows) with primary supply from the OphA (arrowheads). Collaterals to the SPA via the artery of the foramen rotundum (arrow) and the vidian artery (curved arrow) are seen. B, Lateral view of a right vertebral arteriogram demonstrating retrograde filling of the proximally occluded right ECA (curved arrow) via the occipital artery (arrows). The IMA is reconstituted to supply the AVM (open arrows).

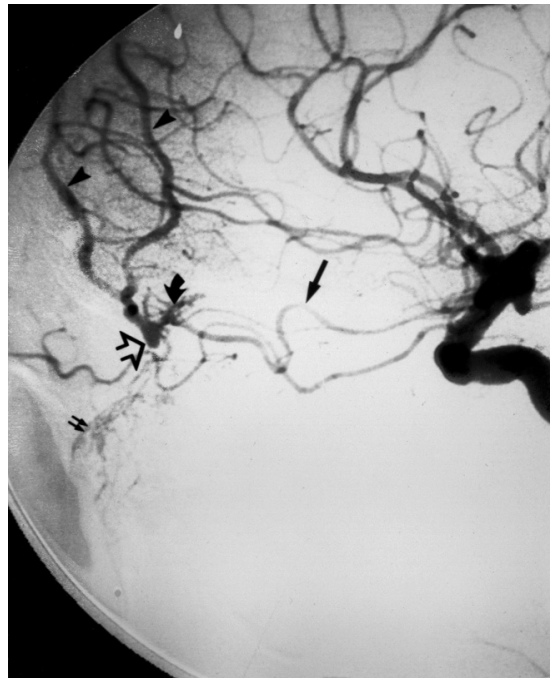

Fig 7. Left internal carotid arteriogram of a 53-year-old woman, who presented with a 4-week history of recurrent epistaxis uncontrolled by AP packs and requiring multiple transfusions. The image reveals a small cerebral AVM with a nidus measuring $<1 \mathrm{~cm}$ (curved arrow). The AVM is fed by an orbitofrontal branch (straight arrow) of the right anterior cerebral artery. Two early draining cortical veins are seen (arrowheads) as well as a small venous aneurysm distal to the nidus (open arrow). A small venous network is opacified in the nasal fossa (double arrow).

alter the treatment protocol, it is important to take note of them. We will discuss a number of different reported etiolo- gies of epistaxis and their implications for the endovascular treatment strategy.

\section{Traumatic Epistaxis}

Although life-threatening hemorrhage associated with maxillofacial trauma is considered rare ${ }^{34}$ massive exsanguinating epistaxis can occur due to laceration of ECA branches. ${ }^{34-36}$ This can be addressed after securing the airway, which may be compromised by bleeding into the oral cavity, mandibular fractures, soft-tissue swelling, and obtundation from traumatic brain injury. Failure to control blood loss with less invasive measures, including manual pressure, nasal packing, suture closure, and surgical ligation of obvious bleeding sites, will prompt either surgical exploration or transarterial embolization. If massive bleeding with severe shock is still present at this time, immediate sacrifice of the ECA may be the safest option. When time permits, however, patient history, CT examination, and contrast extravasation during angiography can indicate the site of bleeding, allowing selective catheterization and embolization as distal as possible to spare normal arterial territories. $^{36}$

When arterial damage leads to pseudoaneurysm formation, patients can present with epistaxis in a delayed fashion. Aside from arising from arteries vascularizing the oronasal cavity (Fig 2), such traumatic pseudoaneurysms can also arise from the ICA along its cervical, petrous (Fig 3), or cavernous (Fig 4) segments. ${ }^{37,38}$ In the case of a traumatic cavernous ICA 

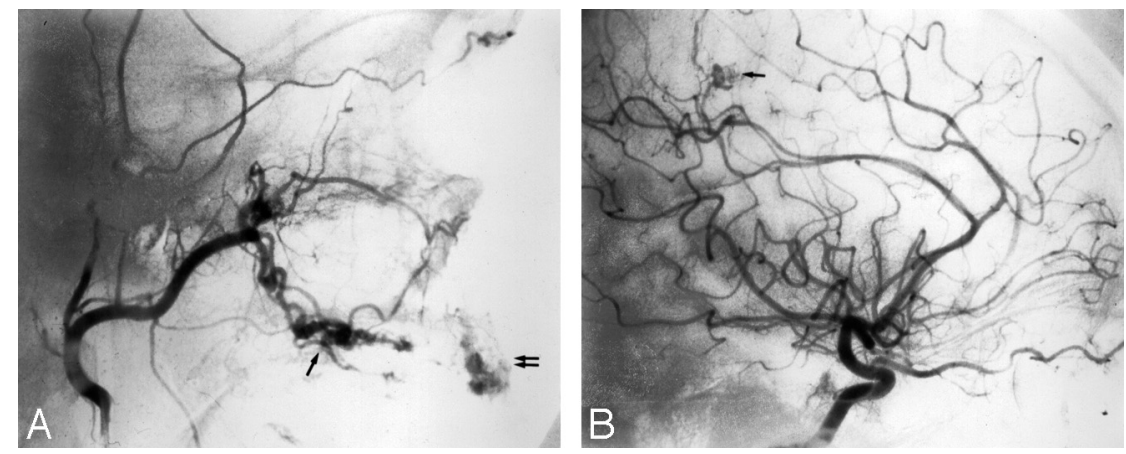

Fig 8. Imaging of a patient with HHT, for whom embolization was requested to treat recurrent epistaxis. A, Right external carotid arteriogram shows typical vascular changes in HHT along the hard palate (arrow) and the premaxilla (double arrow). B. Right internal carotid arteriogram of the same patient shows a small incidental AVM fed by small branches of the pericallosal artery (arrow).

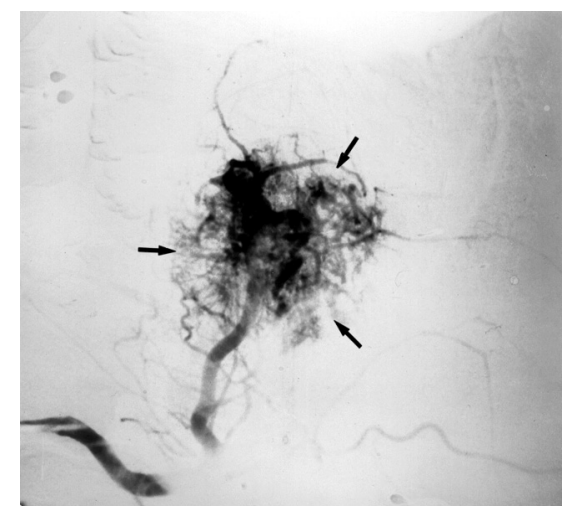

Fig 9. Right external carotid arteriogram in a 12-year-old boy with a juvenile nasopharyngeal angiofibroma, who presented with nasal obstruction and recurrent epistaxis. A hypervascular mass arises from the pterygopalatine portion of the IMA (arrows).

pseudoaneurysm, epistaxis results from rupture into the sphenoid sinus to which the ICA is intimately related along its cavernous segment. ${ }^{39}$ The latent period, which is most likely due to progressive weakening of the arterial wall and erosion of adjacent bone, can vary from several days ${ }^{38}$ to many years, ${ }^{40}$ with most cases presenting within 3 weeks after trauma $(88 \%) .{ }^{41}$ Bleeding is usually characterized by repeated episodes, which become more severe with time, though the first hemorrhage may be fatal in rare instances. ${ }^{38,41}$

Treatment will depend on the vessel involved. In the example shown in Fig 2, surgical ligation of the right AEA was performed because at the time, this was considered to be safer than catheterization and embolization via the OphA. When the pseudoaneurysm arises directly from the ICA and test occlusion of the ICA is tolerated, permanent occlusion of the ICA can be achieved with either detachable balloons or coils. ${ }^{41}$ Resorting to obliteration of the aneurysmal lumen with preservation of the parent vessel when test occlusion is not tolerated may be hazardous due to the fragile nature of the pseudoaneurysmal wall. ${ }^{37}$ Alternatively, endovascular covered stents have been tried for similar lesions but still have technical drawbacks when delivered intracranially. ${ }^{42,43}$

\section{Postoperative Epistaxis}

Surgical trauma to vessels of the sinonasal region can lead to postoperative nasal bleeding. When epistaxis develops shortly after surgery, the causal relationship will be apparent. This is illustrated in Fig 5 by a case of epistaxis several hours after septorhinoplasty. However, delayed epistaxis may also occur, analogous to traumatic epistaxis. ${ }^{41,44}$ For this reason, immediate postoperative angiography has been recommended in cases in which packing was required for sudden arterial bleeding during trans-sphenoidal surgery. ${ }^{44}$ When this does not reveal any abnormalities (eg, occlusion, stenosis, or a pseudoaneurysm), delayed epistaxis is unlikely to occur but cannot be entirely ruled out, because a pseudoaneurysm may still develop. ${ }^{41}$ Moreover, epistaxis may also occur after seemingly uneventful ${ }^{44}$ or even minimally invasive ${ }^{45}$ surgery.

\section{Nontraumatic ICA Aneurysm}

Epistaxis is a very uncommon manifestation of intracavernous ICA aneurysms. When it occurs, a history of head injury is obtainable in $90 \%$ of cases. ${ }^{46}$ In the remaining cases, the aneurysm is either idiopathic ${ }^{47}$ or mycotic. ${ }^{48}$ The diagnostic and treatment strategies in these cases will be similar to those in traumatic ICA aneurysms, as detailed above. In case of a mycotic aneurysm, adjuvant antibacterial or antifungal agents can be administered if an active infection is still suspected.

\section{Arteriovenous Malformation}

Hemorrhage from an arteriovenous malformation (AVM) can present as epistaxis when either the lesion itself or its venous drainage pattern involves the oronasal cavity. Figure 6 demonstrates an AVM of the nose and upper lip in a patient presenting with a history of recurrent epistaxis. Skull base AVMs can present in a similar fashion and can be very challenging to treat due to reduced accessibility. ${ }^{49,50}$ In rare instances, an intracranial AVM draining through pharyngeal veins can cause massive epistaxis when these arterialized veins rupture (Fig 7). ${ }^{51}$ The treatment paradigm in these cases will not differ from that of other AVMs and includes surgery, embolization, radiosurgery, or a combination of these. ${ }^{52}$

\section{Dural Arteriovenous Fistula}

A dural arteriovenous fistula (DAVF) can be asymptomatic or present with a variety of symptoms, including hemorrhage. ${ }^{53-55}$ The aggressiveness of the symptoms were shown to be related to the venous drainage pattern. ${ }^{53}$ DAVFs without cortical venous reflux are considered relatively benign, whereas fistulas producing cortical venous reflux are considered aggressive because they show a high annual event rate. ${ }^{55}$ When a DAVF is located in the anterior fossa, which occurs in 

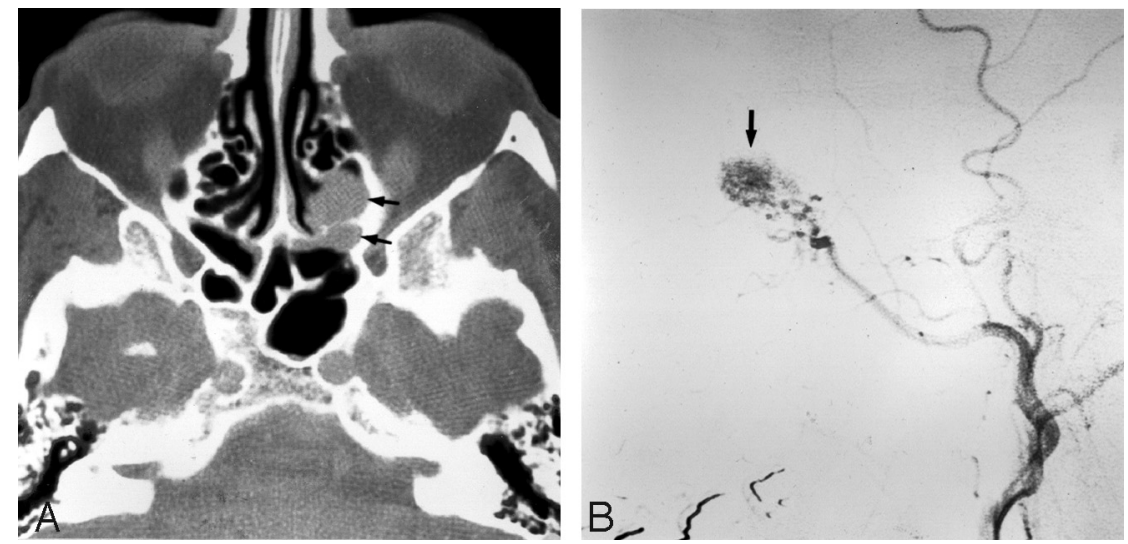

Fig 10. Imaging of a 65-year-old man who presented with intractable epistaxis and whose history included right nephrectomy for renal cell carcinoma 5 years earlier. $A$, Axial CT scan at the level of the ethmoid sinuses shows a soft-tissue mass in the posterior ethmoidal air cells (arrows). B, Left external carotid arteriogram demonstrates the neovascularity (arrow) supplied by the terminal IMA
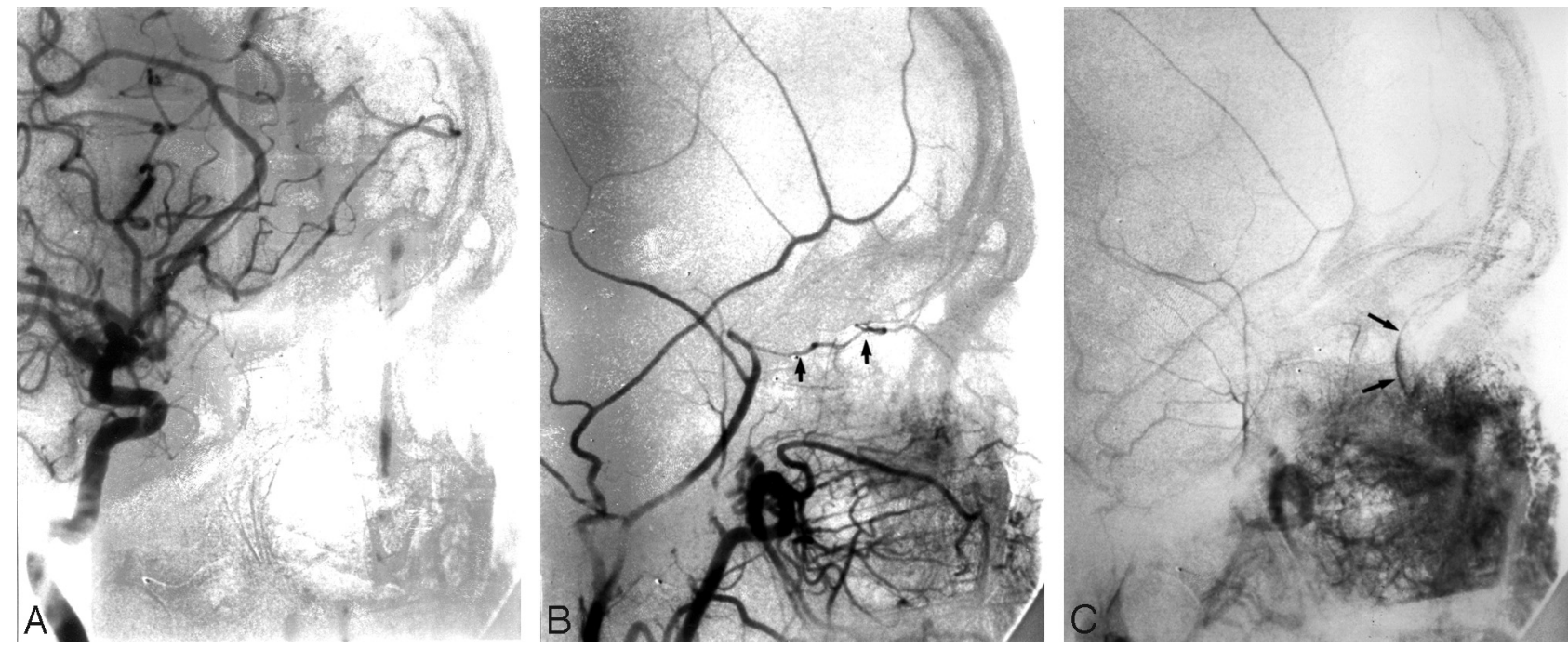

Fig 11. Angiography in a 62-year-old man with right-sided epistaxis, demonstrating a meningo-ophthalmic artery (ie, the OphA arises from the MMA). Selective catheterization of the IMA distal to the origin of the MMA was necessary to perform embolization safely. A, Right internal carotid arteriogram demonstrates the absence of the OphA arising from the internal carotid system. $B$, Right external carotid arteriogram, early arterial phase, reveals the meningo-ophthalmic artery (arrows). $C$, The same image as in $B$, late arterial phase, confirms the choroidal blush (arrows) arising from the external carotid system.

approximately $10 \%$ of cases, ${ }^{56}$ it is supplied by the ethmoidal branches of the ophthalmic artery from 1 or both sides and drains into the superior sagittal sinus via cortical veins. Such lesions always show an aggressive drainage pattern, exhibit a strong male predominance, and present most frequently in the sixth decade. ${ }^{57}$ In rare instances, these can present with epistaxis, presumably due to erosion of the floor of the anterior fossa by aneurysmal dilation of a draining vein. ${ }^{58}$ Endovascular embolization with $n$-butyl cyanoacrylate was shown to be a viable treatment option for these lesions, with a relatively high success rate $(63.6 \%)$ and low complication rate, followed by open surgery in case of failure. ${ }^{57}$

\section{Hereditary Hemorrhagic Telangiectasia}

Hereditary hemorrhagic telangiectasia (HHT), also known as Osler-Weber-Rendu disease, is a systemic autosomal dominant condition characterized by vascular abnormalities of the nose, skin, lung, gastrointestinal tract, and central nervous system. The prevalence of HHT ranges from 1 in 2351 to 1 in 39,216 in different populations. ${ }^{59}$ Epistaxis caused by sponta- neous bleeding from telangiectases of the nasal mucosa is the most common manifestation in these patients (Fig 8). It may be so severe as to require multiple transfusions or so mild that HHT is never suspected. Recurrent epistaxis usually presents during the first 2 decades of life and becomes more severe with time in approximately 2 of 3 patients. Other manifestations that appear later in life include telangiectases of the skin and, less frequently, pulmonary AVMs; central nervous system AVMs (Fig 8); and gastrointestinal telangiectases, AVMs, or angiodysplasias.

The difficulty in treating recurrent epistaxis in patients with HHT is reflected by the multitude of reported treatment options, including chemical, electrical, or ultrasonic cauterization; local or systemic hormone therapy; topical application of fibrin glue; photocoagulation; transarterial embolization; brachytherapy; septal dermoplasty; vessel ligation; bleomycin injections; and the use of nasal obturators. ${ }^{59-61} \mathrm{Be}$ cause none of these provide a definite cure, treatment is aimed at reducing the number and severity of epistaxis episodes. Though transarterial embolization may achieve this goal, ${ }^{30}$ re- 

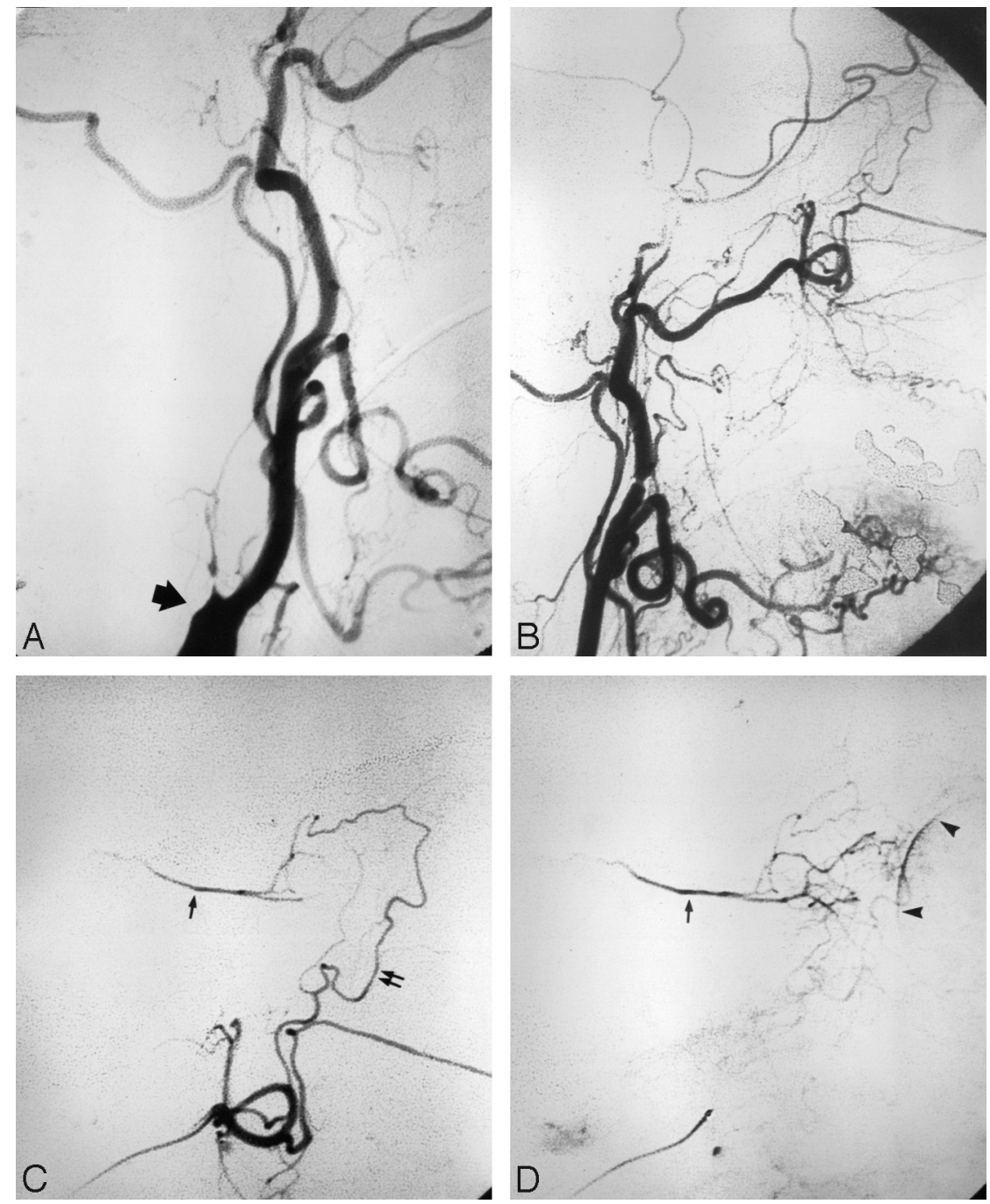

Fig 12. Angiography in a 72-year-old woman with intractable idiopathic epistaxis, who was referred to surgery because an ECA origin of the OphA rendered embolization unsafe. $A$, Left common carotid arteriogram demonstrates ICA occlusion (arrow). B. The same image as A shows no antegrade or retrograde opacification of the OphA. C, Selective left IMA injection, early arterial phase, demonstrates collaterals from the SPA to the OphA (arrow) via an ethmoidal branch (double arrows). D, The same image as in $C$ but in the late arterial phase shows the OphA (arrow) and choroidal blush (arrowheads).

currence rates, requiring re-embolization or surgery, are generally higher in patients with HHT than in patients without HHT. ${ }^{19,62}$ Therefore, permanent proximal occlusion with coils is not advised because this may preclude re-embolization when distal collaterals result in recurrent episodes. ${ }^{62}$ Because mucosal perfusion returns to normal within 2-8 days after embolization, ${ }^{26}$ elective embolization (ie, embolization at a time when the patient is not actively bleeding) will not yield long-term control. ${ }^{19}$

\section{Sinonasal Neoplasms}

Although almost any tumor in the sinonasal region can present with epistaxis, juvenile nasopharyngeal angiofibromas most commonly cause epistaxis requiring embolization. ${ }^{19,28}$ Juvenile nasopharyngeal angiofibromas are benign tumors that occur almost exclusively in young men, with the peak incidence between 14 and 17 years of age. They are highly vascular lesions (Fig 9), spreading via foramina and fissures in the skull base region. The feeding vessels are primarily the IMA or APhA, though tumor spread may lead to the recruitment of a secondary blood supply. Embolization of the accessible feed- ing vessels can be performed to control epistaxis and to prevent excessive bleeding during surgical resection. Small particles $(50-150 \mu \mathrm{m})$ are used to penetrate and occlude intratumoral vessels, by using selective catheter positioning to avoid damage to surrounding tissue. ${ }^{63}$

The remaining list of tumor types that can cause intractable epistaxis is varied and includes hemangioma, hemangiopericytoma, acute myelogenous leukemia, pyogenic granuloma gravidarum, nasopharyngeal carcinoma, malignant fibrous histiocytoma, adenoid cystic carcinoma, and metastatic disease (Fig 10). ${ }^{19,28,64-66}$ Analogous to juvenile nasopharyngeal angiofibromas, epistaxis may initially be controlled with embolization, but depending on the nature of the tumor, some will eventually require surgery and/or external beam radiation. After such aggressive treatment, epistaxis can occur due to residual or recurrent tumor or due to surgical- and radiation-induced damage to blood vessels. Epistaxis in these cases can be life-threatening, prompting rapid angiography, with abnormal findings in most of these cases, which will guide therapeutic choices. $^{67,68}$ 


\section{Treatment Results and Complications}

The ability to halt bleeding with embolization therapy immediately following the procedure has been reported to be between $93 \%$ and $100 \%{ }^{20,23,25,29,31,33}$ When early rebleeds were taken into account, the success rate dropped to $77.3 \%-$ 94.6\%. ${ }^{19,20,25,28,29,32,33}$ The period evaluated for these rebleeds varied from 72 hours ${ }^{28}$ to 33 days. ${ }^{29}$ Retrospective reviews that took late rebleeds into account reported a further drop in the success rate to $71 \%-89.2 \%{ }^{19,20,25,29,31-33}$ One group clearly demonstrated that the success rate depended on the embolization protocol used. ${ }^{23}$ Another report demonstrated the influence of the underlying pathology on the short-term and long-term success rates, with long-term success naturally being lowest in patients with HHT, because these patients have ongoing systematic pathology resulting in new episodes. ${ }^{19}$ In general, the success rates mentioned above best represent the results in idiopathic posterior epistaxis, given the distribution of pathologies in the cited reports.

Complications of embolization can be categorized as being minor transient, major transient, or persistent. Minor transient adverse events include headache, facial pain, jaw pain, trismus, facial edema, facial numbness, facial cold hypersensitivity, paresthesias, mild palate ulceration, altered mental status, groin hematoma, groin pain, or fever. ${ }^{19,20,25,29,33}$ Major transient complications include skin slough, ${ }^{19}$ temporary hemiparesis, ${ }^{20,23}$ temporary monocular visual field loss, ${ }^{28}$ and mucosal necrosis. ${ }^{31,69}$ Persistent complications include facial scarring following ischemia, ${ }^{31}$ monocular blindness, ${ }^{27}$ peripheral facial nerve paralysis, ${ }^{28,70}$ cerebral infarction, ${ }^{19,20,29}$ and ischemic sialadenitis requiring surgery. ${ }^{24}$ Larger series report minor transient complications in $25 \%-59 \%$, major transient in $0 \%-1 \%$, and persistent in $\leq 2 \%$ of cases. ${ }^{19,20,25,29,33}$ Delayed diagnosis of an intranasal neoplasm has also been mentioned as a potential pitfall of embolization. ${ }^{71}$

In comparison, the failure rate of surgical ligation to treat intractable epistaxis has been reported to be between $4.3 \%$ and $33 \% .{ }^{11,13,14,16,72-74}$ With the advent of endoscopic surgery, complication rates of surgery have decreased, with only minor complications being reported, including pain, posterior rhinorrhea, numbness of the palate and nose, nasal crusting, intranasal adhesions, and septal perforation. ${ }^{11,13,14,16,73,74}$ Thus, success and complication rates are quite comparable between surgical ligation and embolization, except that more serious major complications are associated with embolization. ${ }^{75}$ Again, this stresses the need to be aware of angiographic findings that represent a communication between the ECA and the ICA or the OphA. Such findings may represent normal anastomoses, anatomic variants (Fig 11), or acquired collateralizations (Fig 12). When these are encountered, one should consider alteration of the embolization technique accordingly or referral to surgery.

\section{Conclusions}

Transarterial embolization is an accepted treatment option for intractable epistaxis, when epistaxis is refractory to conservative or surgical management. It is, however, associated with a small risk of serious morbidity that occurs when embolic material inadvertently enters the ICA or OphA. Therefore, one should be aware of possible communications between these vessels and the ECA and perform diagnostic angiography before treatment. Such angiography may also reveal less common causes of epistaxis, which would likely have an impact on the treatment strategy.

\section{References}

1. Small M, Murray JA, Maran AG. A study of patients with epistaxis requiring admission to hospital. Health Bull (Edinb) 1982;40:20-29

2. Pallin DJ, Chng YM, McKay MP, et al. Epidemiology of epistaxis in US emergency departments, 1992 to 2001. Ann Emerg Med 2005;46:77-81

3. Walker TW, Macfarlane TV, McGarry GW. The epidemiology and chronobiology of epistaxis: an investigation of Scottish hospital admissions 19952004. Clin Otolaryngol 2007;32:361-65

4. Manfredini R, Gallerani M, Portaluppi F. Seasonal variation in the occurrence of epistaxis. Am J Med 2000;108:759-60

5. Danielides V, Kontogiannis N, Bartzokas A, et al. The influence of meteorological factors on the frequency of epistaxis. Clin Otolaryngol Allied Sci 2002;27:84-88

6. Koh E, Frazzini VI, Kagetsu NJ. Epistaxis: vascular anatomy, origins, and endovascular treatment. AJR Am J Roentgenol 2000;174:845-51

7. Tan LK, Calhoun KH. Epistaxis. Med Clin North Am 1999;83:43-56

8. Viducich RA, Blanda MP, Gerson LW. Posterior epistaxis: clinical features and acute complications. Ann Emerg Med 1995;25:592-96

9. Monte ED, Belmont MJ, Wax MK. Management paradigms for posterior epistaxis: a comparison of costs and complications. Otolaryngol Head Neck Surg 1999;121:103-06

10. Pollice PA, Yoder MG. Epistaxis: a retrospective review of hospitalized patients. Otolaryngol Head Neck Surg 1997;117:49-53

11. Klotz DA, Winkle MR, Richmon J, et al. Surgical management of posterior epistaxis: a changing paradigm. Laryngoscope 2002;112:1577-82

12. Schaitkin B, Strauss M, Houck JR. Epistaxis: medical versus surgical therapy-a comparison of efficacy, complications, and economic considerations. Laryngoscope 1987;97:1392-96

13. Holzmann D, Kaufmann T, Pedrini P, et al. Posterior epistaxis: endonasal exposure and occlusion of the branches of the sphenopalatine artery. Eur Arch Otorhinolaryngol 2003;260:425-28

14. Wiorowski M, Schultz P, Perrot JB, et al. Indications and results of cauterization by endoscopic approach of the sphenopalatine artery in severe posterior epistaxis. Auris Nasus Larynx 2004;31:131-33

15. Stankiewicz JA. Nasal endoscopy and control of epistaxis. Curr Opin Otolaryngol Head Neck Surg 2004;12:43-45

16. Snyderman CH, Goldman SA, Carrau RL, et al. Endoscopic sphenopalatine artery ligation is an effective method of treatment for posterior epistaxis. $\mathrm{Am} \mathrm{J}$ Rhinol 1999;13:137-40

17. Sokoloff J, Wickbom I, McDonald D, et al. Therapeutic percutaneous embolization in intractable epistaxis. Radiology 1974;111:285-87

18. Lasjaunias P, Marsot-Dupuch K, Doyon D. The radio-anatomical basis of arterial embolisation for epistaxis. J Neuroradiol 1979;6:45-53

19. Elden L, Montanera W, Terbrugge K, et al. Angiographic embolization for the treatment of epistaxis: a review of 108 cases. Otolaryngol Head Neck Surg 1994;111:44-50

20. Tseng EY, Narducci CA, Willing SJ, et al. Angiographic embolization for epistaxis: a review of 114 cases. Laryngoscope 1998;108:615-19

21. Berenstein A, Lasjaunias P, Terbrugge K. Surgical Neuroangiography: Clinical and Endovascular Treatment Aspects in Adults. Berlin, Germany: SpringerVerlag; 2004

22. Osborn AG. Diagnostic Cerebral Angiography. Philadelphia: Lippincott Williams \& Wilkins; 1943

23. Vitek J. Idiopathic intractable epistaxis: endovascular therapy. Radiology 1991;181:113-16

24. Duncan IC, Spiro FI, van Staden D. Acute ischemic sialadenitis following facial artery embolization. Cardiovasc Intervent Radiol 2004;27:300-02

25. Fukutsuji K, Nishiike S, Aihara T, et al. Superselective angiographic embolization for intractable epistaxis. Acta Otolaryngol 2008;128:556-60

26. Weaver EM, Chaloupka JC, Putman CM, et al. Effect of internal maxillary arterial occlusion on nasal blood flow in swine. Laryngoscope 1999;109:8-14

27. Ashwin PT, Mirza S, Ajithkumar N, et al. Iatrogenic central retinal artery occlusion during treatment for epistaxis. Br J Ophthalmol 2007;91:122-23

28. Gurney TA, Dowd CF, Murr AH. Embolization for the treatment of idiopathic posterior epistaxis. Am J Rhinol 2004;18:335-39

29. Duncan IC, Fourie PA, le Grange CE, et al. Endovascular treatment of intractable epistaxis: results of a 4-year local audit. S Afr Med J 2004;94:373-78

30. Andersen PJ, Kjeldsen AD, Nepper-Rasmussen J. Selective embolization in the treatment of intractable epistaxis. Acta Otolaryngol 2005;125:293-97

31. Sadri M, Midwinter K, Ahmed A, et al. Assessment of safety and efficacy of arterial embolisation in the management of intractable epistaxis. Eur Arch Otorhinolaryngol 2006;263:560-66

32. Christensen NP, Smith DS, Barnwell SL, et al. Arterial embolization in the 
management of posterior epistaxis. Otolaryngol Head Neck Surg 2005; 133:748-53

33. Oguni T, Korogi Y, Yasunaga T, et al. Superselective embolisation for intractable idiopathic epistaxis. Br J Radiol 2000;73:1148-53

34. Bynoe RP, Kerwin AJ, Parker HH 3rd, et al. Maxillofacial injuries and lifethreatening hemorrhage: treatment with transcatheter arterial embolization. J Trauma 2003;55:74-79

35. Liu WH, Chen YH, Hsieh CT, et al. Transarterial embolization in the management of life-threatening hemorrhage after maxillofacial trauma: a case report and review of literature. Am J Emerg Med 2008;26:516 e3-5

36. Borden NM, Dungan D, Dean BL, et al. Posttraumatic epistaxis from injury to the pterygovaginal artery. AJNR Am J Neuroradiol 1996;17:1148-50

37. Crow WN, Scott BA, Guinto FC Jr, et al. Massive epistaxis due to pseudoaneurysm: treated with detachable balloons. Arch Otolaryngol Head Neck Surg 1992;118:321-24

38. Fontela PS, Tampieri D, Atkinson JD, et al. Posttraumatic pseudoaneurysm of the intracavernous internal carotid artery presenting with massive epistaxis. Pediatr Crit Care Med 2006; 7:260-62

39. Renn WH, Rhoton AL Jr. Microsurgical anatomy of the sellar region. J Neurosurg 1975;43:288-98

40. Simpson RK Jr, Harper RL, Bryan RN. Emergency balloon occlusion for massive epistaxis due to traumatic carotid-cavernous aneurysm: case report. J Neurosurg 1988;68:142-44

41. Chen D, Concus AP, Halbach VV, et al. Epistaxis originating from traumatic pseudoaneurysm of the internal carotid artery: diagnosis and endovascular therapy. Laryngoscope 1998;108:326-31

42. Felber $\mathrm{S}$, Henkes $\mathrm{H}$, Weber $\mathrm{W}$, et al. Treatment of extracranial and intracranial aneurysms and arteriovenous fistulae using stent grafts. Neurosurgery 2004; 55:631-38, discussion 38-39

43. Redekop G, Marotta T, Weill A. Treatment of traumatic aneurysms and arteriovenous fistulas of the skull base by using endovascular stents. J Neurosurg 2001;95:412-19

44. Raymond J, Hardy J, Czepko R, et al. Arterial injuries in transsphenoidal surgery for pituitary adenoma; the role of angiography and endovascular treatment. AJNR Am J Neuroradiol 1997;18:655-65

45. Schmerber S, Vasdev A, Chahine K, et al. Internal carotid false aneurysm after thermocoagulation of the gasserian ganglion. Otol Neurotol 2008;29:673-75

46. Mahmoud NA. Traumatic aneurysm of the internal carotid artery and epistaxis: review of literature and report of a case. J Laryngol Otol 1979; 93:629-56

47. Karkanevatos A, Karkos PD, Karagama YG, et al. Massive recurrent epistaxis from non-traumatic bilateral intracavernous carotid artery aneurysms. Eur Arch Otorhinolaryngol 2005;262:546-49

48. Hurst RW, Judkins A, Bolger W, et al. Mycotic aneurysm and cerebral infarction resulting from fungal sinusitis: imaging and pathologic correlation. AJNR Am J Neuroradiol 2001;22:858-63

49. Koebbe CJ, Horowitz M, Levy EI, et al. Endovascular particulate and alcohol embolization for near-fatal epistaxis from a skull base vascular malformation. Pediatr Neurosurg 2001;35:257-61

50. Kassam AB, Thomas AJ, Zimmer LA, et al. Expanded endonasal approach: a fully endoscopic completely transnasal resection of a skull base arteriovenous malformation. Childs Nerv Syst 2007;23:491-98

51. de Tilly LN, Willinsky R, TerBrugge K, et al. Cerebral arteriovenous malformation causing epistaxis. AJNR Am J Neuroradiol 1992;13:333-34

52. Friedlander RM. Clinical practice: arteriovenous malformations of the brain. N Engl J Med 2007;356:2704-12
53. Cognard C, Gobin YP, Pierot L, et al. Cerebral dural arteriovenous fistulas: clinical and angiographic correlation with a revised classification of venous drainage. Radiology 1995;194:671-80

54. Satomi J, van Dijk JM, Terbrugge KG, et al. Benign cranial dural arteriovenous fistulas: outcome of conservative management based on the natural history of the lesion. J Neurosurg 2002;97:767-70

55. van Dijk JM, terBrugge KG, Willinsky RA, et al. Clinical course of cranial dura arteriovenous fistulas with long-term persistent cortical venous reflux. Stroke 2002;33:1233-36

56. Lasjaunias $\mathrm{P}$, Chiu M, ter Brugge K, et al. Neurological manifestations of intracranial dural arteriovenous malformations. J Neurosurg 1986;64:724-30

57. Agid R, Terbrugge K, Rodesch G, et al. Management strategies for anterior cranial fossa (ethmoidal) dural arteriovenous fistulas with an emphasis on endovascular treatment. J Neurosurg 2009;110:79-84

58. Baskaya MK, Suzuki Y, Seki Y, et al. Dural arteriovenous malformations in the anterior cranial fossa. Acta Neurochir (Wien) 1994;129:146-51

59. Guttmacher AE, Marchuk DA, White RI Jr. Hereditary hemorrhagic telangiectasia. N Engl J Med 1995;333:918-24

60. Fiorella ML, Ross DA, White RI, et al. Hereditary haemorrhagic telangiectasia: state of the art. Acta Otorhinolaryngol Ital 2004;24:330-36

61. Duncan IC, Van Der Nest L. Intralesional bleomycin injections for the palliation of epistaxis in hereditary hemorrhagic telangiectasia. AJNR Am J Neuroradiol 2004;25:1144-46

62. Layton KF, Kallmes DF, Gray LA, et al. Endovascular treatment of epistaxis in patients with hereditary hemorrhagic telangiectasia. AJNR Am J Neuroradiol 2007;28:885-88

63. Turowski B, Zanella FE. Interventional neuroradiology of the head and neck. Neuroimaging Clin N Am 2003;13:619-45

64. Weber W, Henkes H, Metz KA, et al. Haemangiopericytoma of the nasal cavity. Neuroradiology 2001;43:183-86

65. Wong GK, Chan KK, Yu SC, et al. Treatment of profuse epistaxis in patients irradiated for nasopharyngeal carcinoma. ANZ J Surg 2007;77:270-74

66. Choudhary S, MacKinnon CA, Morrissey GP, et al. A case of giant nasa pyogenic granuloma gravidarum. J Craniofac Surg 2005;16:319-21

67. Low YM, Goh YH. Endovascular treatment of epistaxis in patients irradiated for nasopharyngeal carcinoma. Clin Otolaryngol Allied Sci 2003;28:244-47

68. Luo CB, Teng MM, Chang FC, et al. Transarterial embolization of acute external carotid blowout syndrome with profuse oronasal bleeding by $n$-butylcyanoacrylate. Am J Emerg Med 2006;24:702-08

69. Guss J, Cohen MA, Mirza N. Hard palate necrosis after bilateral internal maxillary artery embolization for epistaxis. Laryngoscope 2007;117:1683-84

70. Metson R, Hanson DG. Bilateral facial nerve paralysis following arterial embolization for epistaxis. Otolaryngol Head Neck Surg 1983;91:299-303.

71. Ortiz JM, Bhattacharyya N. Management pitfalls in the use of embolization for the treatment of severe epistaxis. Ear Nose Throat J 2002;81:178-83

72. Rockey JG, Anand R. A critical audit of the surgical management of intractable epistaxis using sphenopalatine artery ligation/diathermy. Rhinology 2002; 40:147-49

73. Nouraei SA, Maani T, Hajioff D, et al. Outcome of endoscopic sphenopalatine artery occlusion for intractable epistaxis: a 10-year experience. Laryngoscope 2007;117:1452-56

74. Abdelkader M, Leong SC, White PS. Endoscopic control of the sphenopalatine artery for epistaxis: long-term results. J Laryngol Otol 2007;121:759-62

75. Cullen MM, Tami TA. Comparison of internal maxillary artery ligation versus embolization for refractory posterior epistaxis. Otolaryngol Head Neck Surg 1998;118:636-42 